\title{
Simulation Studies of the Prepulse-Main-Pulse XeCl Discharge Lasers with Magnetic Switching
}

\author{
R. Sorkina ${ }^{1,2, \star}$, F. A. van Goor ${ }^{1}$, and W. J. Witteman ${ }^{1}$ \\ 1 University of Twente, Dept. of Applied Physics, P.O. Box 217, NL-7500 AE Enschede, The Netherlands (Fax: +31-53/338065) \\ 2 Institute of Physics, Estonian Academy of Sciences, Riia 142, Tartu, Estonia
}

Received 10 June 1992/Accepted 28 August 1992

\begin{abstract}
A self-consistent model of a self-sustained discharge $\mathrm{XeCl}$ laser ( $\mathrm{Ne} / \mathrm{Xe} / \mathrm{HCl}$ mixture) with prepulse-mainpulse excitation and magnetic switching which leads to high efficiency operation is described. The validity of the model is confirmed by comparing the results of the calculations with the measured time dependences of discharge voltage, current and lasing pulse for different operation modes as well as by comparing the results with the dependences of the laser output energy and efficiency on the charging voltage and capacitance of the pulse forming network for two different laser heads. The numerical evaluation has shown that our developed laser system operates under optimum conditions.
\end{abstract}

PACS: $42.55 . \mathrm{Gp}$

Potential applications of excimer lasers as sources of UV radiation in industries, especially in photochemistry and materials processing require very high average power lasers. Commercially available excimer lasers produce hundreds of watts of average power at an efficiency of up to $2.5 \%$ in some cases 3\% (e.g., LPX240i or LAMBDA4000). A number of laboratories are working on the development of excimer lasers with $1 \mathrm{~kW}$ average power by means of a fast flowing gas circulation system. A breakthrough in this development was obtained by the introduction of the so-called prepulse-main-pulse technique in which the prepulse is used for the avalanche ionization process during the breakdown phase whereas the main pulse is applied under quasi-steady-state conditions [1-4]. The introduction of passive magnetic switches for isolation of low-impedance sustainer and high-impedance spiker circuits instead of railgap switches enables long-life operation capability of the laser at high repetition rates [2-4]. With this new excitation technique efficiencies of $3-5 \%$ were achieved $[1,3-5]$.

\footnotetext{
* Present address: Air Research Laboratory, RIVM, P.O. Box 1, NL-3720 BA Bilthoven, The Netherlands
}

Computer modeling is a useful tool for investigating the physical processes occurring in the active media of excimer lasers and the influence of the large number of parameters that are involved. It supplements the experiments and will be used to optimize the development of various laser designs.

In this paper we present a theoretical model of a high efficient discharge $\mathrm{XeCl}$ laser with prepulse-main-pulse and the magnetic switching technique. The results of the computer simulations are compared with the experimental ones of the lasers developed at the Twente University of Technology [4]. The model is based on the standard excitation schemes of He [6] and $\mathrm{Ne}$ [7] based mixtures, which are in good agreement with the experimental data, including time dependences of the densities of discharge species. Although computer simulations were mentioned in $[1,3]$ and shortly described in [8] (not including the Boltzmann equation for the electron distribution), we shall describe the complete model of a discharge $\mathrm{XeCl}$ laser with the advanced excitation circuit and improved kinetics. We shall discuss and compare the results of the simulations with the experiments for different modes of laser operation and for different laser heads.

\section{Model Description}

The model of a discharge $\mathrm{XeCl}$ laser consists of the Boltzmann equation for the electron distribution function, a set of kinetic equations for the densities of the discharge plasma components and photons in the cavity and a set of equations describing the laser excitation circuit. Spatial uniformity of the active medium is assumed. This approach of a zero-dimensional modelling has shown to be reasonable in describing laser performance by comparing the zero- and one-dimensional calculations for He based mixtures with experiments $[6,9]$.

The steady-state Boltzmann equation $[10,11]$ for the relaxed electron distribution function takes into account elastic, inelastic, superelastic, and electron-electron collisions cited in Table 1 . The algorithm for solving the Boltzmann equation [9] has been described in detail in [12]; the method is similar to that described in [13]. The rate constants of 
Table 1. Reactions allowed for in the model, their rate constants and references

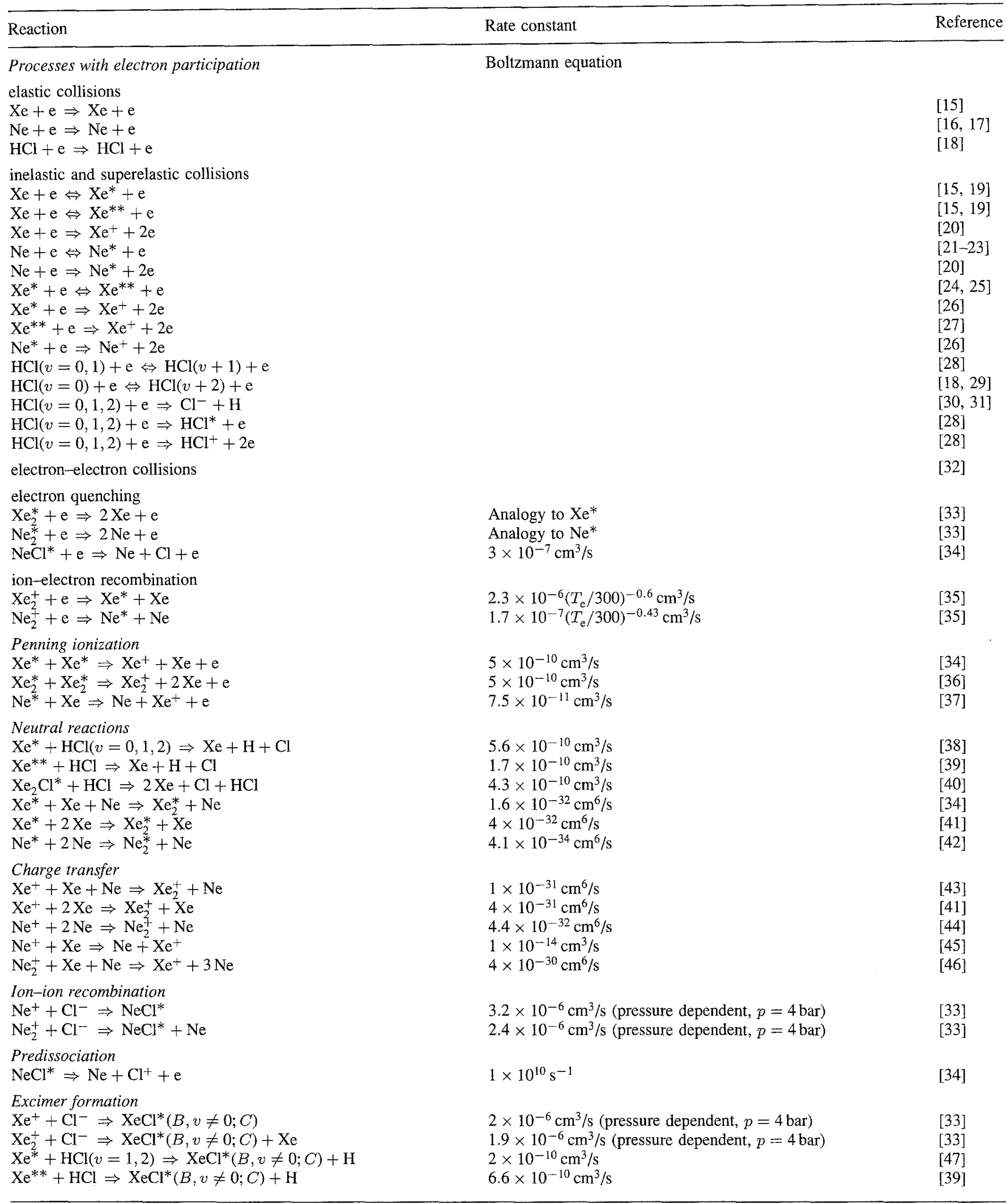


Table 1 (continued)

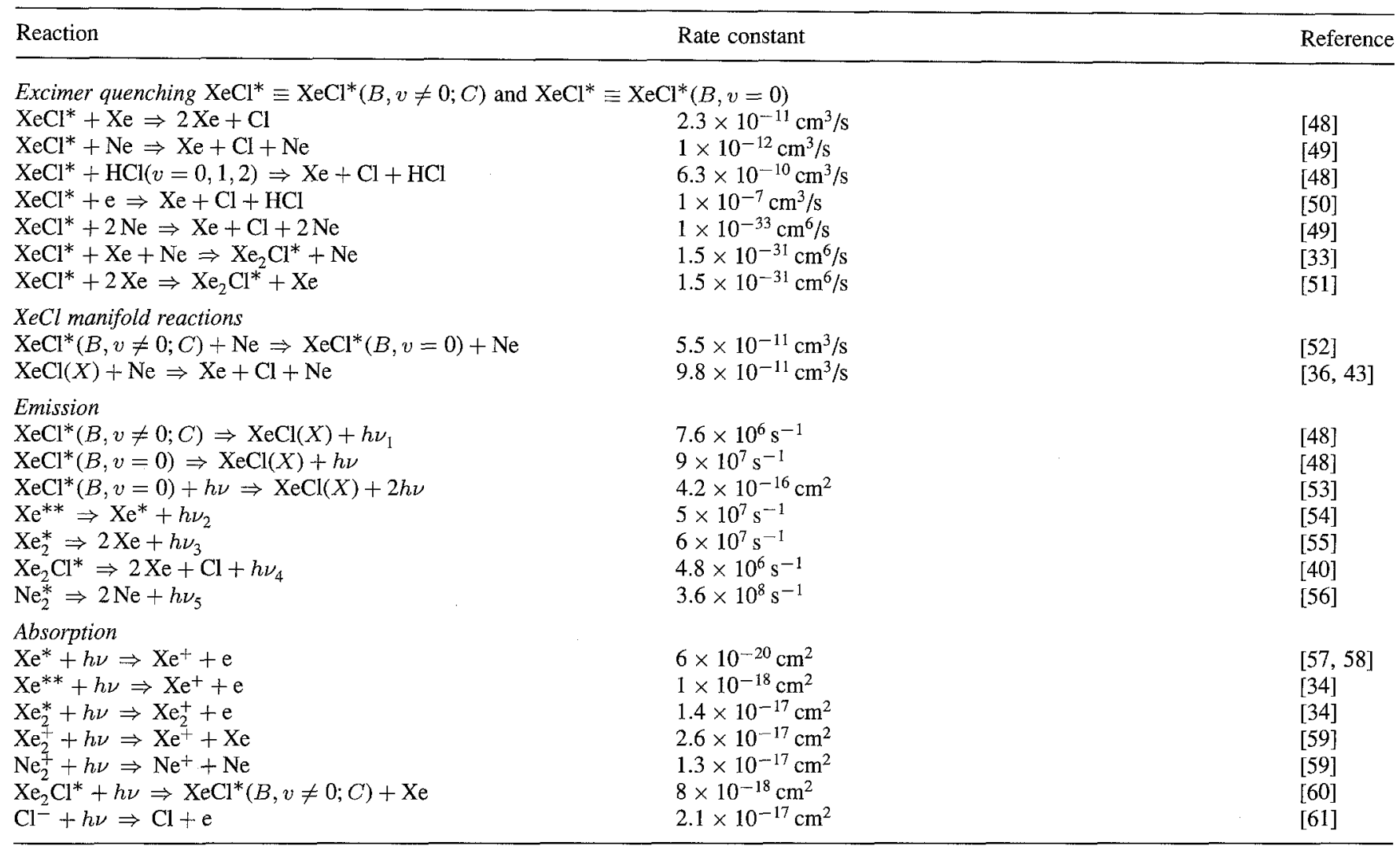

$T_{\mathrm{e}}$ is the average electron energy over the distribution in $K$

the elementary processes with the participation of electrons are found as the resultants of the cross sections of the corresponding processes with the electron distribution function and they are used for solving the set of kinetic equations. The specific energy depositions in the processes with participation of electrons were calculated with the help of the resultant solution.

The kinetic model of chemical reactions in the active medium of a discharge $\mathrm{XeCl}$ laser with Ne buffer gas describes the time dependences of the densities of 22 plasma components - $\mathrm{Xe}, \mathrm{Xe}^{*}, \mathrm{Xe}^{* *}, \mathrm{Xe}^{+}, \mathrm{Xe}_{2}^{*}, \mathrm{Xe}_{2}^{+}, \mathrm{Ne}, \mathrm{Ne}^{*}$, $\mathrm{Ne}^{+}, \mathrm{Ne}_{2}^{*}, \mathrm{Ne}_{2}^{+}, \mathrm{HCl}, \mathrm{HCl}(v=1), \mathrm{HCl}(v=2), \mathrm{Cl}^{-}, \mathrm{e}$, $\mathrm{XeCl}^{*}(B, v \neq 0 ; C), \mathrm{XeCl}^{*}(B, v=0), \mathrm{XeCl}(X), \mathrm{Xe}_{2} \mathrm{Cl}^{*}$, $\mathrm{NeCl}^{*}$, and photons ( $h \nu$ in Table 1 ) - by solving a set of 19 kinetic equations allowing for three conservation laws for charge and $\mathrm{Ne}$ and Xe nuclei. The integration of the set of kinetic equations is performed by using the subroutine DIFSUB using the method of Gear [14]. The reactions taken into account, their rate constants and references are cited in Table 1. The excited states of the $\mathrm{XeCl}$ molecule are divided into the lasing level $\mathrm{XeCl}^{*}(B, v=0)$ and the unrelaxed vibrational manifold $\mathrm{XeCl}^{*}(B, v \neq 0 ; C)$. The heteronuclear component $\mathrm{NeXe}^{+}$is omitted, as it was found to be very weakly bound $[62,63]$ and its presence has a small effect on the model predictions. The photon density is described assuming a homogeneous gain and absorption along the active medium length.

The objects of the investigation were two X-ray preionized discharge $\mathrm{XeCl}$ lasers with prepulse-main-pulse and magnetic switching having different electrode spacings $d$ (15 mm and $25 \mathrm{~mm})$. An equivalent scheme of the laser excitation circuit is shown in Fig. 1. The thyratron in the prepulse circuit was modelled by an inductance and an exponentially decreasing voltage $U_{\mathrm{T}}=U_{\mathrm{pp}}+A\left(1-\mathrm{e}^{t / \tau}\right)$ within the commutation period of $20 \mathrm{~ns}$ [64] $\left(U_{\mathrm{pp}}\right.$ is the charging voltage, $A$ is a dimension factor) as well as by an active resistance $R_{\mathrm{t}}=0.15 \Omega$ during the conductance period. The pulse forming network was modelled by a lumped capacitor $\mathrm{C}_{\mathrm{pfn}}$ or by $20 \mathrm{~L}-\mathrm{C}$ loops representing the pulse forming line. The ferrite magnetic switch was modelled by taking into account

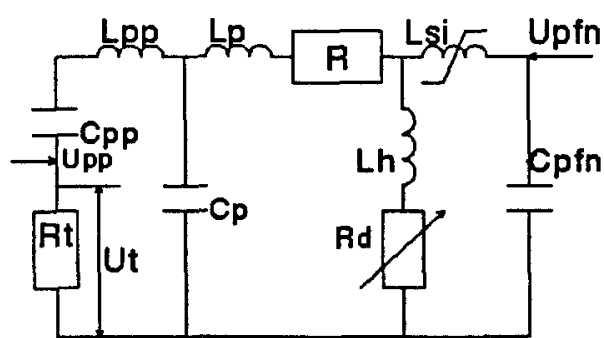

Fig. 1. Equivalent circuit of the $\mathrm{XeCl}$ laser with prepulse-main-pulse and the magnetic switching excitation technique used in the model. $U_{\mathrm{T}}$ : thyratron voltage exponentially decreasing during the commutation period, $R_{\mathrm{t}}$ : thyratron active resistance during the conductance period. $R_{\mathrm{d}}$ represents the laser discharge nonlinear resistance and $\mathrm{L}_{\mathrm{si}}$ the time dependent inductance of the magnetic switch (max. flux density of $0.32 \mathrm{~T}$ and coercive force $\mathrm{H}_{\mathrm{c}}$ of $\left.13.6 \mathrm{~A} / \mathrm{m}\right) . \mathrm{C}_{\mathrm{pp}}=5.4 \mathrm{nF} ; \mathrm{L}_{\mathrm{pp}}=400 \mathrm{nH}$; $\mathrm{L}_{\mathrm{p}}=6 \mathrm{nH} ; \mathrm{R}=0.1 \Omega ; \mathrm{L}_{\mathrm{h}}=8 \mathrm{nH}$ 

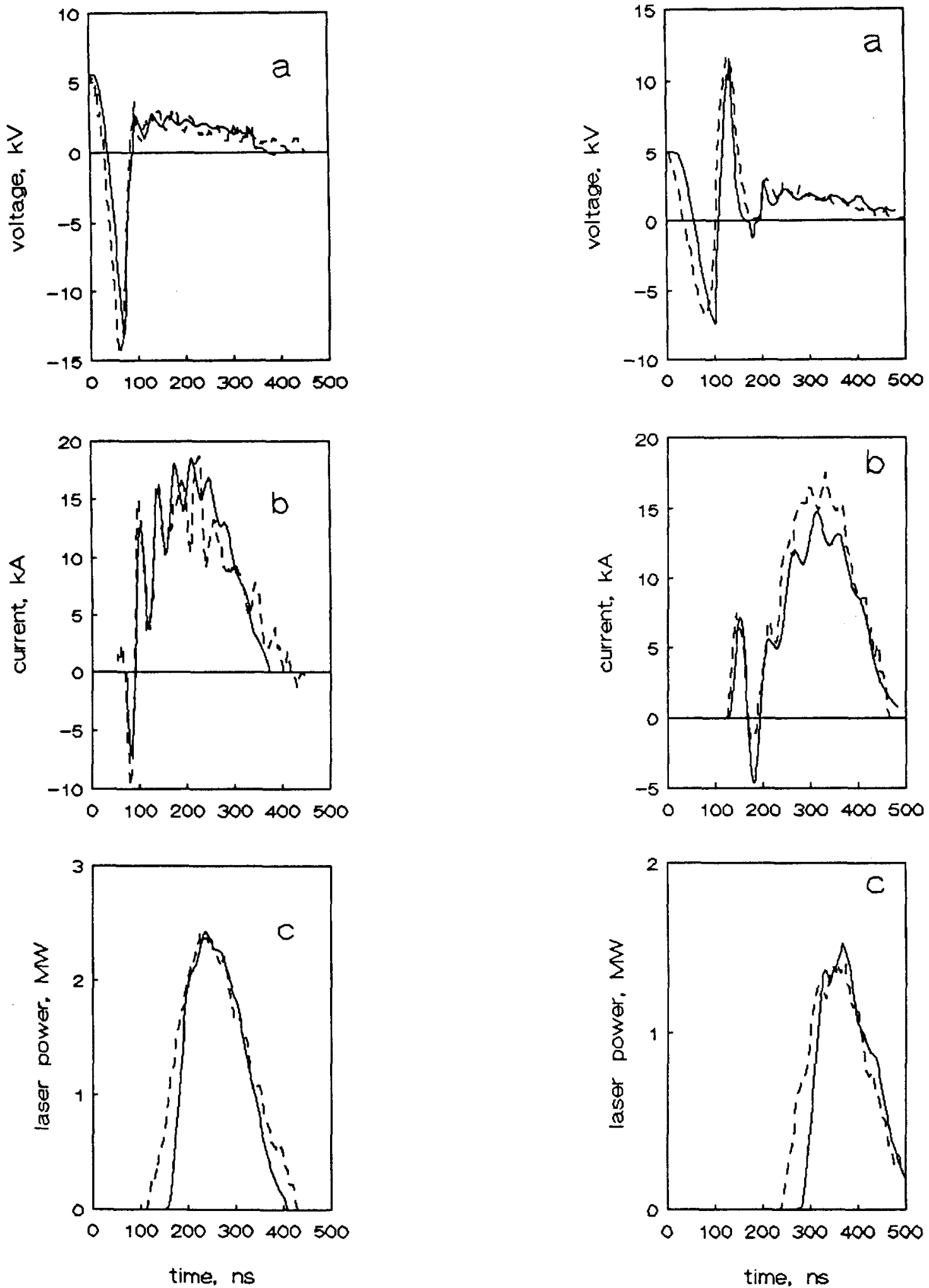

Fig. 2. Calculated (full) curves and measured (broken) curves of the temporal behaviour of: a voltage on the discharge gap; $\mathbf{b}$ the discharge current (measured one in arbitrary units); $\mathbf{c}$ the lasing pulse (measured one in arbitrary units). Laser is operating in the switch mode; electrode spacing $15 \mathrm{~mm}$ and a race track magnetic switch of $12 \mathrm{~cm}^{2}$ cross section and volume of $1600 \mathrm{~cm}^{3}$ (max. flux density of $0.32 \mathrm{~T}$ and coercive force $\mathrm{H}_{\mathrm{c}}$ of $13.6 \mathrm{~A} / \mathrm{m}$ ) is used. $\mathrm{C}_{\mathrm{pfn}}=440 \mathrm{nF} ; \mathrm{C}_{\mathrm{p}}=6.4 \mathrm{nF} ; \mathrm{U}_{\mathrm{pfn}}=5.6 \mathrm{kV}$; $\mathrm{U}_{\mathrm{pp}}=40 \mathrm{kV}$. The other components are given in Fig. 1. Mixture: 4 bar $\mathrm{Ne}, 15 \mathrm{mbar} \mathrm{Xe}, 1.5 \mathrm{mbar} \mathrm{HCl}$

Fig. 3. Calculated (full) curves and measured (broken) curves of the temporal behaviour of: a voltage on the discharge gap; $\mathbf{b}$ the discharge current; $\mathbf{c}$ the lasing pulse. Laser is operating in the overshoot mode, electrode spacing is $15 \mathrm{~mm}$ and $1600 \mathrm{~cm}^{3}$ magnetic material is used. $C_{p f n}=400 \mathrm{nF} ; C_{p}=6.4 n F ; U_{p f n}=5 \mathrm{kV} ; U_{p p}=19 \mathrm{kV}$. The other components are as in Fig. 1. Mixture: 4 bar Ne, 14.5 mbar Xe, $1.3 \mathrm{mbar}$ $\mathrm{HCl}$ 
the measured B-H hysteresis curve. The equations for the magnetic switch inductance $\mathrm{L}_{\mathrm{si}}$ related to the $\mathrm{B}-\mathrm{H}$ hysteresis loop and depending on the current flowing through $\mathrm{L}_{\mathrm{si}}$ were derived analogously to [65] but for a rectangular saturable inductor configuration. Two algorithms were used to solve the set of circuit equations. This was done because of the large value of the discharge gap resistance $R_{\mathrm{d}}$ in the initial stages of the discharge and the possible instability caused by that fact. To avoid this instability the discharge current density $i$ obtained by the product of the electron drift velocity $v_{\mathrm{dr}}$ and the electron density was used in the first algorithm. This algorithm was employed up to $i=50 \mathrm{~A}$ and after that the second algorithm was switched on to calculate the discharge resistance. The solution of the circuit equations gives the voltage across the discharge gap and the discharge current at time $t$. The electric field strength $E(t)=U(t) / d$ is used as the entrance parameter in the Boltzmann equation.

\section{Results and Discussion}

The calculated and measured time dependences of the voltage across the discharge gap, discharge current, and lasing pulse for the discharge $\mathrm{XeCl}$ laser with prepulse-main-pulse and magnetic switching, operating in the so-called magnetic switch mode [3] are shown in Fig. 2. The laser electrode separation is $15 \mathrm{~mm}$ and $1600 \mathrm{~cm}^{3}$ of magnetic material is used in the form of rectangular ferrite blocks. The laser mixture is 4 bar $\mathrm{Ne}, 15 \mathrm{mbar} \mathrm{Xe}$, and $1.5 \mathrm{mbar} \mathrm{HCl}$. The mainpulse forming network capacitor, $\mathrm{C}_{\mathrm{PFN}}=440 \mathrm{nF}$, is pulse charged within a few microseconds (not shown in Fig. 2) up to $5.6 \mathrm{kV}$, after which the prepulse is fired just after the $\mathrm{X}$-ray preionization pulse. The $5.6 \mathrm{kV}$ of the pulse forming network capacitor is about equal to twice the steady-state voltage of the laser discharge. The charging voltage of the prepulse capacitor is $34.4 \mathrm{kV}$. The prepulse changes the polarity across the electrodes and charges the voltage of the peaking capacitor $C_{p}$ to a negative value while initiating the electron avalanche. At the same time the saturable inductor $\mathrm{L}_{\mathrm{si}}$ is brought into saturation. After the breakdown the discharge current reverses its direction and the energy of the pulse-forming network is deposited into the discharge.

Because the electron density of about $5 \times 10^{14} \mathrm{~cm}^{-3}$ is already produced by the prepulse there will be impedance matching between the PFN and the discharge. The PFN energy is then deposited into the discharge under quasisteady-state conditions, which has a favourable effect on the efficiency of the laser. The peaks on the main current pulse are caused by oscillations in the peaking capacitor loop. The calculated laser output energy of $342 \mathrm{~mJ}$ is in good agreement with the measured value of $350 \mathrm{~mJ}$.

The calculated and measured time dependences of the voltage on the discharge gap, the discharge current and the lasing pulse for the same $\mathrm{XeCl}$ laser operating in the socalled overshoot mode [4] are shown in Fig. 3. The prepulse capacitor is now charged to $14 \mathrm{kV}$, the laser mixture is $4 \mathrm{bar}$ $\mathrm{Ne}, 14.5 \mathrm{mbar} \mathrm{Xe}$, and $1.3 \mathrm{~m}$ bar $\mathrm{HCl}$. Again the prepulse voltage is applied directly after the $\mathrm{X}$-ray preionization of the active volume. After the thyratron switching the peaking capacitor $\mathrm{C}_{\mathrm{p}}$ is charged. The voltage across the discharge gap is now also changing its polarity, but the negative prepulse is not high enough to cause the breakdown of the laser. When the peaking capacitor is charged negatively the magnetic switch is saturated and the peaking capacitor can be recharged in the positive direction. This causes a voltage overshoot and consequently a high-voltage positive prepulse is applied. Breakdown of the electrode gap is achieved and the energy from the peaking capacitor is deposited into the discharge, a positive prepulse current is flowing and the discharge voltage drops. The subsequent small negative current and the oscillating structure on the main current pulse are caused by the oscillations in the peaking capacitor loop. At the moment the prepulse current starts to flow, the magnetic switch is going into saturation. Impedance matching of the discharge is now obtained and the energy of the main pulse stored in the PFN is deposited into the discharge under high efficiency conditions. The calculated and measured laser output energies are about equal to $209 \mathrm{~mJ}$.

Figure 4 shows the calculated time-integrated energy flow diagram in the discharge $\mathrm{XeCl}$ laser operating in the overshoot mode. Negative energy means deposition in superelastic collisions. The electrical efficiency for this type of $\mathrm{XeCl}$ laser is higher than for $\mathrm{XeCl}$ laser with a standard excitation scheme and a short lasing pulse [7] which has no impedance matching. The energy deposition into the processes with high threshold energies, such as the direct ionization of $\mathrm{Xe}$ and the excitation of $\mathrm{Ne}$, is less than in a $\mathrm{XeCl}$ laser with a standard excitation circuit [7] because of

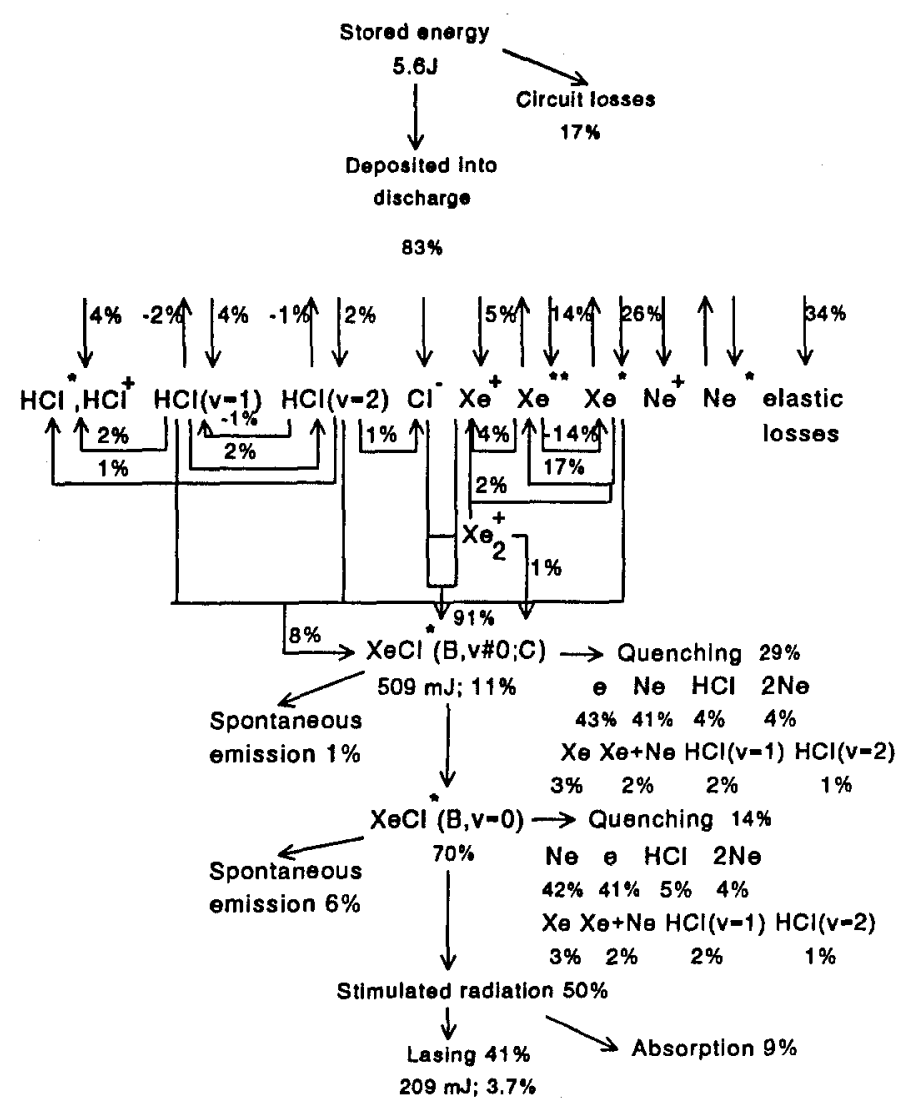

Fig. 4. Energy flow diagram in the high efficient discharge XeCl laser operating in the overshoot mode. Parameters as in Fig. 3 


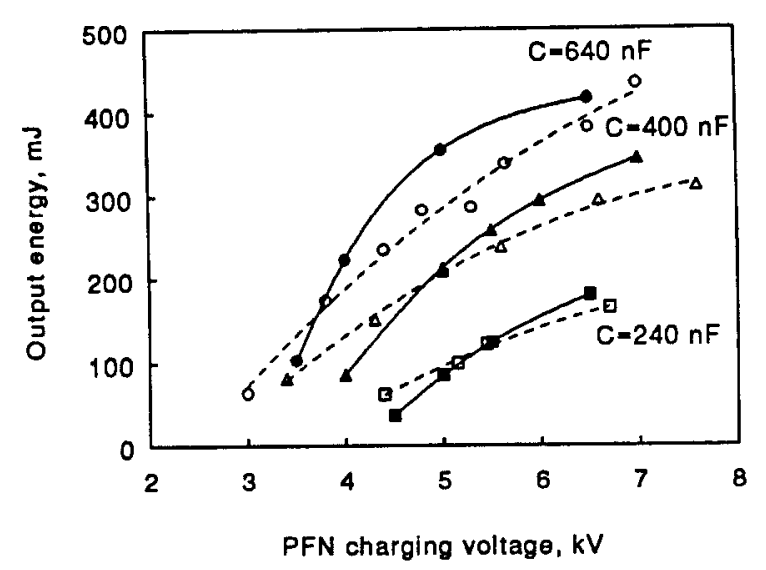

Fig. 5. Calculated (full) curves and measured (broken) curves of the dependences of the laser output energy on the pulse-forming network changing voltage for the different PFN capacites. Other parameters as in Fig. 3

the lower $E / P$ value ( $E$-electric field strength, $P$-pressure). However, electron energy losses in the elastic collisions are higher because of the same reason. The quenching of excimer $\mathrm{XeCl}^{*}$ molecules by electrons is comparable with that of $\mathrm{Ne}$ atoms. In the case of a short pulse laser the quenching by Ne atoms was larger [7].

For the overshoot mode operation the calculated and measured dependences of the laser output energy on the pulse forming network charging voltages for different PFN capacities are shown in Fig. 5. Conversion efficiencies of $3-4 \%$ of the discharge energy including the prepulse can be achieved with this type of laser excitation. When we choose a lower PFN capacity the optimum efficiency of the laser is nearly constant over a larger range of PFN charging voltage values than for the larger PFN capacities. For the overshoot mode operation the calculated and measured dependences of the laser output energy on the pulse forming network capacity for different PFN charging voltages are shown in Fig. 6. The calculated dependences of the laser output energy on the gas mixture composition give an optimum mixture composition which is in substantial agreement with that observed experimentally. The calculated dependence of the laser energy on the output mirror reflectivity gives an optimum mirror reflectivity of $70-80 \%$ which is in agreement with the one used in the laser $(70 \%)$.

The calculations for another discharge $\mathrm{XeCl}$ laser with the anologous excitation scheme but with electrode separation of $25 \mathrm{~mm}$ and $2160 \mathrm{~cm}^{3}$ of magnetic switching material and operating in the overshoot mode were also carried out. The calculated and measured dependences of the laser efficiency on the pulse-forming network charging voltage for this laser are shown in Fig. 7. The maximum efficiency is achieved for about $300 \mathrm{~kW} / \mathrm{cm}^{3}$ pumping peak power density. A short voltage rise time and sufficient high prepulse voltage must be applied in order to excite the whole preionized discharge volume. Scaling calculations using a pulse forming line in the sustainer circuit, show that increasing the length of the pumping pulse does not improve the laser efficiency because of the $\mathrm{HCl}$ depletion.

In conclusion, a model of the physical processes in a high efficient discharge $\mathrm{XeCl}$ laser with prepulse-main-pulse and

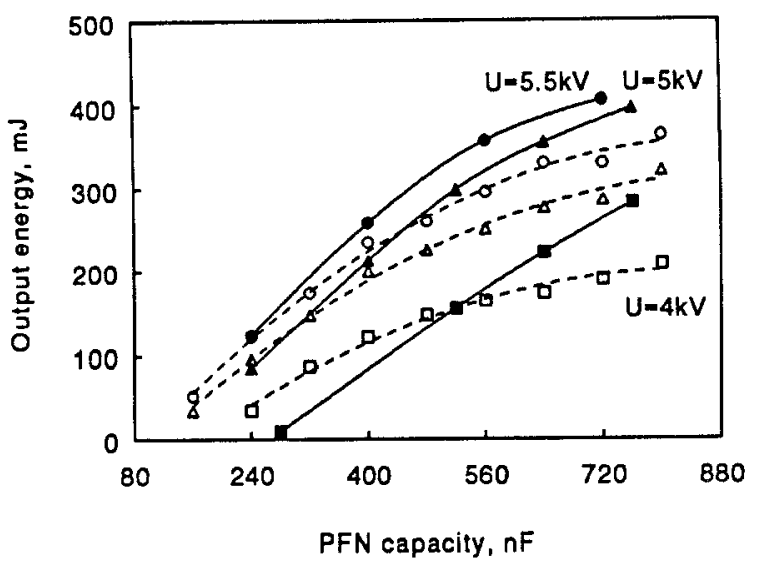

Fig. 6. Calculated (full) curves and measured (broken) curves of the dependences of the laser output energy on the pulse-forming network capacity for the different PFN voltages. Other parameters as in Fig. 3

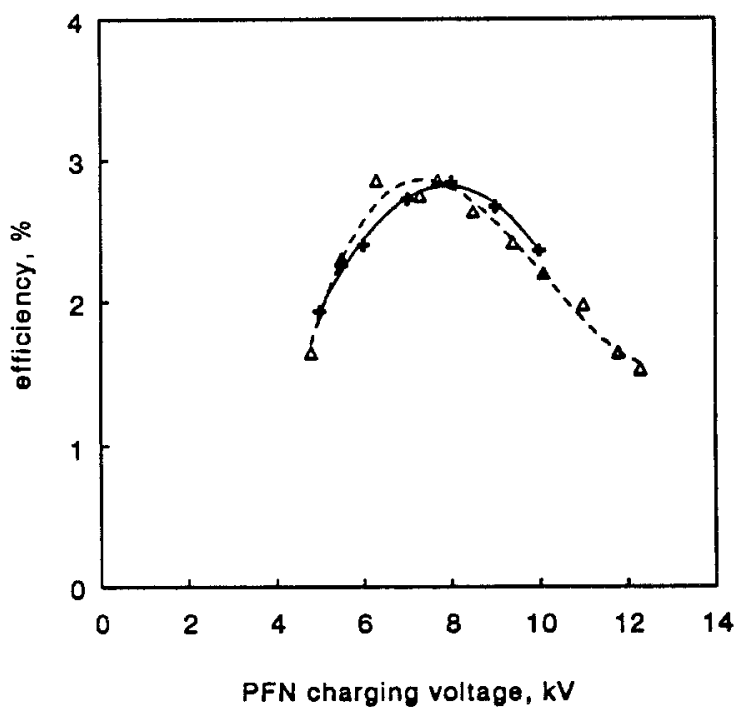

Fig. 7. Calculated (full) curves and measured (broken) curves of the dependences of the laser efficiency on the pulse-forming network charging voltage. Laser is operating in the overshoot mode, electrode spacing $25 \mathrm{~mm}, 12 \times 180 \mathrm{~cm}^{3}$ magnetic material is used. $\mathrm{C}_{\mathrm{pfn}}=432 \mathrm{nF}$; $\mathrm{C}_{\mathrm{p}}=3.5 \mathrm{nF} ; \mathrm{U}_{\mathrm{pp}}=24 \mathrm{kV}$. The components are given in Fig. 1. Mixture: 4 bar $\mathrm{Ne}, 14.5$ mbar Xe, 1.3 mbar $\mathrm{HCl}$

magnetic switching is developed. Comparison of calculated and measured results for two operation modes and for two laser heads was carried out. The results of the computer simulations are in reasonable agreement with the measured ones, which indicates the validity of the used model. The efficiency of the laser operation in the overshoot mode (3.7\%) is higher than in the switch mode (3.4\%). This is due to the smaller amount of energy deposited in the prepulse circuit of the overshoot mode. Efficiency optimization has shown that the laser built in our laboratory is operating under optimum conditions.

Acknowledgements. The authors would like to thank M. Trentelman and J. Timmermans for providing the experimental measurements. 
This work was supported by the Dutch Foundation for Fundamental Research on Matter (FOM) and by the Netherlands Centre for Laser Research (NCLR).

\section{References}

1. W.H. Long, M.J. Plummer, E.A. Stappaerts: Appl. Phys. Lett. 43, 735-737 (1983)

2. R.S. Taylor, K.E. Leopold: Appl. Phys. Lett. 46, 335-337 (1985)

3. C.H. Fisher, M.J. Kushner, T.E. DeHart, J.P. McDaniel, R.A. Petr, J.J. Ewing: Appl. Phys. Lett. 48, 1574-1576 (1986)

4. J.W. Gerritsen, A.L. Keet, G.J. Ernst, W.J. Witteman: Opt. Commun. 77, 395-396 (1990)

5. J.M. Hueber, B.L. Fontaine, Ph.C. Delaporte, B.M. Forestier, M.L. Sentis: Opt. Commun. 85, 237-240 (1991)

6. V. Mihkelsoo, P. Miidla, V. Peet, A. Sherman, R. Sorkina, E. Tamme, A. Treshchalov; J. Phys. B: At. Mol. Opt. Phys. 22, 1489 1504 (1989)

7. R. Sorkina: Modelling of Physical Processes in a Discharge XeCl laser. Ph.D. Thesis, Estonian Academy of Sciences (1990)

8. M.N. Kobhio, B.L. Fontaine, J.M. Hueber, P. Delaporte, B.M. Forestier, M.L. Sentis: 8th Int'1 Symp. on Gas Flow and Chemical Lasers, SPIE, Vol. 1397, pp. 555-558 (1990)

9. R. Sorkina: J. Phys. D: Appl. Phys. 23, 806-812 (1990)

10. K. Smith, R.M. Thomson: Computer Modelling of Gas Lasers (Plenum, New York 1978) p. 127

11. L.A. Schlie: J. Appl. Phys. 47, 1397-1407 (1976)

12. E. Tamme, A. Sherman: Proc. Acad. Sci. Estonian SSR: Phys. Math. 35, 302-307 (1986) (in Russian)

13. S.D. Rockwood: Phys. Rev. A 8, 2348-2358 (1973)

14. C.W. Gear: Commun. Assoc. Comp. Machin. 14, 185-190 (1971)

15. M. Hayashi: J. Phys. D: Appl. Phys. 16, 581-589 (1983)

16. A.G. Robertson: J. Phys. B: At. Mol. Phys. 5, 648-664 (1972)

17. D.F. Register, S. Trajmar: Phys. Rev. A 29, 1785-1792 (1984)

18. N.T. Padial, D.W. Norcross, L.A. Collins: Phys. Rev. A 27, 141 148 (1983)

19. N.J. Mason, W.R. Newell: J. Phys. B: At. Mol. Phys. 20, 13571377 (1987)

20. D. Rapp, P. Englander-Golden: J. Chem. Phys. 43, 1464-1479 (1965)

21. S.J. Buckman, P. Hammond, G.C. King, F.H. Read: J. Phys. B: At. Mol. Phys. 16, 4219-4236 (1983)

22. M.H. Phillips, L.W. Anderson, C.C. Lin: Phys. Rev. A 23, 2751 2754 (1981)

23. M.H. Phillips, L.W. Anderson, C.C. Lin, R.E. Miers: Phys. Lett. A 82, 404-406 (1981)

24. H.A. Hyman: Phys. Rev. A 24, 1094-1095 (1981)

25. S.T. Chen, A.C. Gallagher: Phys. Rev. A 17, 551-560 (1978)

26. D. Ton-That, M.R. Flannery: Phys. Rev. A 15, 517-526 (1977)

27. H.A. Hyman: Phys. Rev. A 20, 855-859 (1979)

28. B.M. Penetrante, J.N. Bardsley: J. Appl. Phys. 54, 6150-6153 (1983)

29. K. Rohr, F. Linder: J. Phys. B: At. Mol. Phys. 9, 2521-2537 (1976)
30. J.N. Bardsley, J.M. Wadehra: J. Chem. Phys. 78, 7227-7234 (1983)

31. W. Domcke, C. Mundel: J. Phys. B: At. Mol. Phys. 18, 4491-4509 (1985)

32. L.A. Schlie: J. Appl. Phys. 47, 1397-1407 (1976)

33. H. Hokazono, K. Midorikawa, M. Obara, T. Fujioka: J. Appl. Phys. 56, 680-690 (1984)

34. L.A. Levin, S.E. Moody, E.L. Klosterman, R.E. Center, J.J. Ewing: IEEE J. QE-17, 2282-2289 (1981)

35. M.A. Biondi: Applied Atomic Collision Physics, Vol. 3, Gas Lasers (Academic, New York 1982) p. 178

36. F. Kannari, A. Suda, M. Obara, T. Fujioka: IEEE J. QE-19, 1587 1600 (1983)

37. R.H. Neynaber, S.Y. Tang: J. Chem. Phys, 70, 4272-4276 (1979)

38. J.H. Kolts, J.E. Velazco, D.W. Setser: J. Chem. Phys. 71, 1247$1263(1979)$

39. J.K. Ku, D.W. Setser: Appl. Phys. Lett. 48, 689-691 (1986)

40. G. Marowsky, R. Sauerbrey, F.K. Tittel, W.L. Wilson: Chem. Phys. Lett. 98, 167-171 (1983)

41. Ch.A. Brau: In Excimer Lasers, 2nd edn., ed. by Ch.K. Rhodes, Topics Appl. Phys., Vol. 30 (Springer, Berlin, Heidelberg 1984)

42. D.L. Huestis, R.M. Hill, H.H. Nakano, D.C. Lrents: J. Chem. Phys. 69, 5133-5139 (1978)

43. M. Maeda, A. Takahashi, T. Mizunami, Y. Miyazoe: Jpn. J. Appl. Phys. 21, 1161-1169 (1982)

44. A. Vitols, H. Oskam: Phys. Rev. A 5, 2618-2622 (1972)

45. R.J. Johnson: J. Chem. Phys. 68, 2991-2993 (1978)

46. C.B. Collins, F.W. Lee: J. Chem. Phys. 69, 5381-5389 (1980)

47. R.S.F. Chang: J. Chem. Phys. 76, 2943-2948 (1982)

48. G. Inoue, J.K. Ku, D.W. Setser: J. Chem. Phys. 80, 6006-6019 (1984)

49. T.G. Finn, R.S.F. Chang, L.J. Palumbo, L.F. Champagne: Appl. Phys. Lett. 36, 789-791 (1980)

50. G.C. Tisone, J.M. Hoffman: IEEE J. QE-18, 1008-1020 (1982)

51. H.P. Grieneisen, Hu Xue-Jing, K.L. Kompa: Chem. Phys. Lett. 82, $421-426(1981)$

52. T.D. Dreiling, D.W. Setser: J. Chem. Phys. 75, 4360-4378 (1981)

53. T.H. Johnson, H.E. Cartland, T.C. Genoni, A.M. Hunter: J. Appl. Phys. 66, 5707-5725 (1989)

54. G. Inoue, J.K. Ku, D.W. Setser: J. Chem. Phys. 81, 5760-5774 (1984)

55. D.J. Eckstrom, H.H. Nakano, D.C. Lorents, T. Rothem, J.A. Betts, M.E. Lainhart, D.A. Dakin, J.E. Maenchen: J. Appl. Phys. 64, 1679-1690 (1988)

56. B. Schneider: J. Chem. Phys. 61, 3240-3243 (1974)

57. C. Duzy, H.A. Hyman: Phys. Rev. A 22, 1878-1883 (1980)

58. K.J. McCann, M.R. Flannery: Appl. Phys. Lett. 31, 599-601 (1977)

59. W.R. Wadt: J. Chem. Phys. 73, 3915-3926 (1980)

60. D.B. Geohegan, J.G. Eden: Chem. Phys. Lett. 139, 519-524 (1986)

61. D.E. Rothe: Phys. Rev. 177, 93-99 (1969)

62. J.R. Pratt: J. Chem. Phys. 76, 3433-3439 (1982)

63. S.P. Zagrebin: Sov. Opt. Spectrosc. 62, 264-272 (1987)

64. T.B. Fogelson, L.N. Breusova, L.N. Vagin: Pulsed Hydrogen Thyratrons (Energija, Moscow 1974) p. 49 (in Russian)

65. M. Stockton, E.L. Neau, J.P. VanDevender: J. Appl. Phys. 53, 2765-2767 (1982) 